\title{
ТЕРРИТОРИАЛЬНАЯ ОРГАНИЗАЦИЯ СЕТИ ОБРАЗОВАТЕЛЬНЫХ УЧРЕЖДЕНИЙ КАК СОЦИАЛЬНЫЙ ФАКТОР РЕАЛИЗАЦИИ ПРАВА НА ДОСТУПНОСТЬ ОБРАЗОВАНИЯ В СУБЪЕКТАХ СКФО РФ И РЕСПУБЛИКЕ ЮЖНАЯ ОСЕТИЯ
}

Задачей исследования послужило формирование знаний о состоянии и гарантированности права человека на образование для выработки рекомендаций для применения в процессе фактической интеграции образовательных пространств Российской Федерации и Республики Южная Осетия.

Законодательство об образовании постоянно стремится к совершенствованию. Применяются новые правовые механизмы регулирования сферы образования В новейшей истории В Российской Федерации новый закон об образовании был принят в 2012 г., в Южной Осетии законы принимались в 2008 г. и 2017 г. В определенной степени применение законодательных актов необходимо корректировать, внося в них изменения или принимая акты подзаконного характера

В статье проведен сравнительный анализ фактической степени гарантированности права на образование в Республике Южная Осетия и Северо-Кавказских республиках Российской Федерации, образовательные комплексы которых наиболее близко соотносимы с образовательным комплексом Южной Осетии. Обобщается правоприменительная практика по вопросам защиты прав детей на образование. Выявлены социальные риски, существенно влияющие на реализацию права человека на образование в России и Южной Осетии. Прежде всего, сделан акцент на вопросе физической реализации права на образование, зависящей от тер- риториальной организации системы общеобразовательных учреждений.

Недостаточность мест в общеобразовательных организациях влечет за собой их переуплотненность, нарушение санитарных норм и правил осуществления образовательного процесса. Система зачисления требует как нормативного совершенствования, так и информационной прозрачности.

Представляется, что иные, альтернативные муниципальным учреждениям, формы присмотра и ухода за детьми, получения ими дошкольного образования обеспечат доступность услуг дошкольного образования. С этой целью необходима целенаправленная государственная политика в отношении открытия и развития частных дошкольных общеобразовательных организаций.

На основе анализа социальных факторов, влияющих на реализацию прав и свобод человека, в дальнейшем возможно сформулировать правовые механизмы, нейтрализующие негативное влияние этих факторов на степень фактической реализации прав человека, в том числе способствовать правильной корректировке действующего законодательства России и Южной Осетии об образовании.

Ключевые слова: право на образование, социальные факторы, реализация права, физическая доступность образования.

\section{THE LOCATION OF EDUCATIONAL INSTITUTIONS AS A FACTOR OF SOCIAL} REALIZATION OF THE RIGHT TO EDUCATION IN THE REPUBLICS

OF THE NORTH-CAUCASUS FEDERAL DISTRICT OF THE RUSSIAN FEDERATION AND THE REPUBLIC OF SOUTH OSSETIA

The aim of the study is the formation of knowledge about the state and guarantee of the human right to education to develop recommendations for use in the actual integration of educational spaces of the Russian Federation and the Republic of South Ossetia

The legislation on education is constantly striving for improvement. New legal mechanisms to regulate the sphere of education are used. In the recent history of the Russian Federation, a new law on education was adopted in 2012, in South Ossetia, laws were adopted in 2008 and 2017 . To some extent, the application of legislative acts should be ad- justed by making changes to them or by adopting acts of subordinate nature.

The article presents a comparative analysis of the actual degree of guarantee of the right to education in the Republic of South Ossetia and the North-Caucasus republics of the Russian Federation, whose educational complexes are most closely correlated with the educational complex of South Ossetia. The article summarizes the law enforcement practice on the protection of children's rights to education. Social risks that significantly affect the realization of the human right to education in Russia and South Ossetia are identified. First,

\footnotetext{
1 Исследование выполнено при финансовой поддержке РФФИ и Министерства образования и науки Республики Южная Осетия в рамках научного проекта № 19-511-07005
} 
the emphasis is placed on the physical realization of the right to education, which depends on the territorial organization of the system of educational institutions.

The lack of places in general education institutions entails their overcrowding, violation of sanitary norms and rules of the educational process. The enrollment system requires both regulatory improvement and information transparency.

A promising area of availability of pre-school education services is the development of variable forms of work with children who do not attend pre-school educational institutions. To this end, work is needed to encourage and assist citizens in opening private pre-school institutions.

Конституция Российской Федерации, устанавливая право человека на образование, тем самым определяет обязанность государства и муниципальных образований предоставлять места детям в образовательных организациях, сохранять их в достаточном количестве и расширять сеть имеющихся образовательных организаций.

Принцип доступности образования состоит из различных составляющих. Конвенция о борьбе с дискриминацией в области образования и статья 13 Международного пакта об экономических, социальных и культурных правах в систему гарантирования государством права на образование включает не только экономическую доступность, но и физическую доступность. Безопасная физическая досягаемость образования обеспечивается посредством посещения общеобразовательной организации на разумном географическом удалении, либо использованием современных дистанционных технологий в обучении.

Конституционный Суд Российской Федерации в Постановлении от 15 мая 2006 г. №5-П разъясняет [9, р. 27-43], что, осуществляя собственное нормативное регулирование, субъекты Российской Федерации и муниципальные образования должны учитывать, что государственная политика определяет образование как приоритетное направление, основываясь на принципах единства федерального культурного и образовательного пространства и общедоступности образования.

Физическая реализация права на образование зависит от территориальной организации системы образовательных учреждений, построенной как в России, так и в Южной Осетии по поселенческому принципу.

«Конституционные провозглашения должны дополняться правовыми предписаниями, содержащимися в источниках позитивного права, а также соответствующим механизмом правового воздействия, юридической практикой, правовой идеологией, сформировавшейся на юрисдикционной территории данного государства». В публикациях авторы отмечают, что только в этом случае можно говорить о создании системы гарантирования реализации конституционных принципов и норм, в том числе закрепляющих систему прав и свобод человека и гражданина [5, p. 24-28].

Выявить социальные риски, которые возникают в системе образования, возможно путем обзо-
Based on the analysis of social factors affecting the realization of the rights and freedoms of the individual, in the future it is possible to formulate legal mechanisms, neutralizing the negative impact of these factors on the degree of actual implementation of human rights, as well as to facilitate the proper adjustment of the existing legislation of Russia and South Ossetia on education

Key words: the right to education, social factors, realization of the right, physical accessibility of education.

ра обращений граждан в адрес Уполномоченных по правам человека и Уполномоченных по правам ребенка, анализа результатов прокурорских проверок, решений судебных инстанций. Эмпирическая база ограничивается в настоящем исследовании статистическими материалами указанных органов Ставропольского края, республики Ингушетия, Кабардино-Балкарской республики

В докладах уполномоченных по правам ребенка обозначаются вопросы осуществления и исполнения прав несовершеннолетних в характерных сферах их жизни, ставшие объектом внимания Уполномоченных, органов исполнительной власти в текущем году.

Тематика обращений граждан и организаций в Ставропольском крае к уполномоченному по правам ребенка в 2018 году составила: 19,96\% о защите прав детей на образование, из них 40 о реализации прав детей на дошкольное образование, 30 жалоб на действия педагогических работников, администрации образовательных учреждений, 16 обращений по вопросам организации образовательного процесса, 9 о реализации прав детей на начальное образование, 15 иных обращений, касающихся прав детей на образование.

Несмотря на активное обновление и расширение в Ставропольском крае сети детских дошкольных образовательных организаций, число обращений с жалобами на отказ в предоставлении мест в детских садах не снижается

По состоянию на 31 декабря 2018 года система дошкольного образования края включала в себя 831 организацию, суммарной проектной мощностью на 122913 мест. Кроме того, 4 индивидуальных предпринимателя (г. Ставрополь, г.-К. Кисловодск и г. Михайловск - 2), осуществляют лицензированный вид деятельности по реализации образовательных программ дошкольного образования, с общим количеством на 417 мест для детей дошкольного возраста.

По данным Минобразования Ставропольского края, 132937 детей в 2018 году было охвачено дошкольным образованием, в том числе: в возрасте до трех лет - 18554 ребенка, в возрасте от 3 до 7 лет - 112461 ребенок.

В Ставропольском крае в прошедшем 2018 году дополнительно создано 329 мест, в 2017 году 410).

Увеличение количества мест достигалось как за счет строительства и введения в эксплуатацию 
1 нового дошкольного учреждения (г. Ставрополь), так и за счет реконструкции, капитального ремонта и внутренних резервов дошкольных образовательных организаций. Тем самым уровень доступности дошкольного образования для детей от трех до семи лет обеспечен на 100 процентов на сегодняшний день.

Вместе с тем отмечаем, что проблема обеспеченности детей до трех лет доступностью к образованию характерна для регионов СКФО. $88,68 \%$ детей указанного возраста в Ставропольском крае имеют возможность посещать детские сады Это обусловлено объективными причинами Во-первых, увеличением числа детского населения за счет миграционных процессов, а во-вторых, отставанием ввода в эксплуатацию необходимых социальных объектов в микрорайонах активной жилищной застройки от темпов ввода в эксплуатацию вновь построенного жилья

Не менее актуальными остаются и вопросы реализации прав детей на начальное образование. В связи с чем в поле зрения Уполномоченного по правам ребенка в Ставропольском крае в 2018 году находились 9 обращений $(8,2 \%)$ по вопросам приема детей в первые классы [3]. Нагрузка на некоторые образовательные организации особенно в городах края превышена более чем на $7 \%$.

В 2018 году 4 письменных обращений в адрес Уполномоченного по правам человека в Республике Ингушетия касались вопросов, связанных с трудностями при определении родителями детей в общеобразовательные учреждения республики

Например, к Уполномоченному с письменным заявлением обратилась многодетная мать с просьбой оказать помощь в определении ее детей в школу-интернат Малгобекского района.
После изучения материалов заявительницы, было установлено, что ее семья находится в трудной жизненной ситуации, является малообеспеченной.

В связи с необходимостью периодических выездов за пределы республики для лечения третьего ребенка-инвалида детства, заявительница просила помочь в определении ее детей в интернат.

В рамках рассмотрения данного заявления, Уполномоченным было направлено обращение на имя директора школы-интернат Малгобекского района, с просьбой оказать содействие в устройстве детей заявительницы.

В результате рассмотрения обращения с руководством образовательного учреждения была достигнута договоренность и двое детей заявительницы приняты в школу-интернат Малгобекского района [1]

Впервые в Кабардино-Балкарской республике в 2018 году за шесть лет на вторую позицию вышли обращения и жалобы по вопросам реализации прав ребенка в образовательной среде, которые за последние три года увеличились в три раза (19\%). Нарушались права детей с инвалидностью в связи с отказами в приеме в коррекционные школы-интернаты, при наличии мест, в вопросах доступности дошкольного образования детей данной категории, реорганизации образовательных организаций и интернатных учреждений, обеспечения бесплатным питанием детей из многодетных семей, нарушения организации питания детей с ОВЗ. Также имеют место конфликты между участниками образовательного процесса, применение непедагогических методов воспитания (каждое второе обращение сопровождается конфоликтом). Статистические данные за период 2016-2018 годы представлены в таблице 1 [2].

Тематика обращений граждан к уполномоченному по правам ребенка

Таблица 1 в Кабардино-Балкарской Республике в динамике за 2016-2018 гг. (в \%)

\begin{tabular}{|c|c|c|c|c|}
\hline \multirow{2}{*}{ № } & \multirow{2}{*}{ Классификация обращений } & \multicolumn{3}{|c|}{ Динамика по годам (\%) } \\
\hline & & 2016 г. & 2017 г. & 2018 r \\
\hline 1. & $\begin{array}{l}\text { Личные права несовершеннолетних, имя и гражданство } \\
\text { ребенка }\end{array}$ & 5,0 & 5,0 & 3,0 \\
\hline 2. & Воспитание ребенка в семье, его содержание & 24,0 & 23,0 & 24,0 \\
\hline 3. & Жилищные и имущественные права ребенка & 16,0 & 15,0 & 10,0 \\
\hline 4. & Права ребенка в сфере образования & 13,0 & 19,0 & 17,0 \\
\hline 5. & Права ребенка в сфере здравоохранения & 10,0 & 5,0 & 9,0 \\
\hline 6. & $\begin{array}{l}\text { Меры поддержки семьям, имеющим несовершеннолет- } \\
\text { них детей }\end{array}$ & 9,0 & 7,0 & 12,0 \\
\hline 7. & Опека и попечительство над несовершеннолетними & 4,0 & 8,0 & 4,0 \\
\hline 8. & Безопасность детей, насилие и жестокое обращение & 5,0 & 3,0 & 6,0 \\
\hline 9. & $\begin{array}{l}\text { Обращения на действия (бездействия) должностных лиц } \\
\text { по соблюдению прав и законных интересов детей }\end{array}$ & 10,0 & 12,0 & 13,0 \\
\hline 10. & Трудовые отношения & 0 & 1,0 & 1,0 \\
\hline 11. & Обращения осужденных & 1,0 & 2,0 & 1,0 \\
\hline 12. & Иные & 3,0 & - & - \\
\hline
\end{tabular}


По вопросу зачисления детей-инвалидов в интернатные (коррекционные) образовательные организации законодатель достаточно четко урегулировал вопрос, и причины отказа детям, что они должны обучаться только в общеобразовательной организации, являются несостоятельными.

Согласно п.4 ст.79 Федерального закона от 29 декабря 2012 г. №273-Ф3 «Об образовании в Российской Федерации» для обучающихся с ограниченными возможностями здоровья может быть организовано обучение как совместно с другими обучающимися, так и в отдельных классах, группах или в отдельных организациях, осуществляющих образовательную деятельность. Таким образом, закон предусмотрел существование инклюзивного и одновременно интегрированного, специального (коррекционного) образования.

В 2017 году имели резонанс в обществе вопросы реорганизации образовательных организаций. В последние два года при реорганизации или ликвидации образовательных учреждений основным аргументом становится бюджетное финансирование. Кроме того, при проведении реорганизационных мероприятий грубо нарушается последовательность процедурных мер, установленных гражданским законодательством, в связи с чем приходилось неоднократно вмешиваться Уполномоченному и надзорным органам.

Количество детей, охваченных дошкольным образованием в Кабардино-Балкарской Республике, на 31 декабря 2017 г., составляло 52701 человек (52 \% от общего количества детей дошкольного возраста). По сравнению с показателями 2013 года (41014 человек) количество детей, получающих дошкольное образование, увеличилось на 11687 человек (28,5\%).

В ходе реализации Республиканской стратегии в рамках государственной программы модернизации региональных систем дошкольного образования в республике создано 4485 мест в 89 образовательных учреждениях, реализующих программу дошкольного образования, из которых:

путем строительства и ввода в эксплуатацию 9 дошкольных образовательных учреждений создано 1240 мест;

путем реконструкции 19 дошкольных образовательных учреждений создано 910 мест;

путем капитального ремонта 61 дошкольного образовательного учреждения создано 2335 мест.

На сегодняшний момент обеспечена стопроцентная доступность образовательных услуг для дошкольников от трех до семи лет. Помощью в достижении указанных показателей является развитие в системе дошкольного образования государственно-частного партнерства. В КБР 4 частных дошкольных организации с охватом 237 детей.

Кроме того, частным дошкольным организациям предоставляются субсидии на возмещение затрат, возникающих в связи с оказанием образовательных услуг по предоставлению дошкольного образования. Так, в 2017 г. на финансовое обеспечение получения дошкольного образования в частных дошкольных образовательных организациях было выделено из республиканского бюджета 7,7 млн рублей.

В рамках реализации мероприятий, направленных на повышение доступности дошкольного образования и создание дополнительных мест для реализации образовательных программ дошкольного образования и (или) присмотра и ухода за детьми, продолжается работа по увеличению охвата детей в возрасте от полутора до трех лет дошкольными образовательными услугами. На начало 2018 года в 180 учреждениях работают 258 групп для детей в возрасте от полутора до трех лет, в которых дошкольными образовательными услугами охвачено 7511 детей ранней возрастной группы. На 1 января 2018 г. численность детей в возрасте от полутора до трех лет, поставленных на учет для предоставления места в дошкольной организации, составила 5662 чел.

Существенную роль в решении данной проблемы играют органы местного самоуправления.

Так, создано 115 дополнительных дошкольных мест для детей ранней возрастной группы, для детей от 3 до 7 лет - 393 дополнительных места. На 1 января 2018 г. создано 548 при запланированных 260.

На сегодняшний день более остро стоит вопрос обеспечения местами в дошкольных учреждениях детей в возрасте от 2 месяцев до 3 лет и эту проблему предстоит решать органам власти в ближайшие годы [2]

На состоявшемся 22.03.2019 расширенном заседании коллегии Министерства просвещения, науки и по делам молодёжи КБР отмечено, что основное направление деятельности - это создание новых мест и современных условий в образовательных организациях, формирование новой технологической среды в системе образования, обновление содержания образования, развитие инклюзивного образования, повышение эфффективности молодёжной политики, формирование условий для реализации проектного подхода в управлении. Общий объём привлечённых из федерального бюджета субсидий превысил 1 млрд 53 млн рублей.

В рамках мероприятий, которые проводились в 2018 году по реализации приоритетного проекта «Создание современной образовательной средь для школьников", одним из важных результатов стало то, что 32 школы занимаются в две смены, а доля обучающихся, занимающихся во вторую смену, снизилась до 9,4 процента. Завершено строительство здания лицея №1 на 825 мест в Нарткале, введена в эксплуатацию средняя школа на 96 мест в селе Ташлы-Тала, начато возведение школы в шестом микрорайоне Нальчика на 1224 места. В 2019 году предусмотрено начало строительства общеобразовательной школы в Чегеме и станице Солдатской, а также строительство 29 зданий (пристроек) к функционирующим учреждениям дошкольного образования для создания двух тысяч дополнительных мест для детей в возрасте до трёх лет. Всего планируется 
создать 3860 мест в 48 учреждениях. В 2018 году построено два детских сада - в сёлах Аргудан и Белая Речка. Параллельно ведётся строительство 19 пристроек к действующим детсадам для создания 860 дополнительных мест для детей раннего возраста.

07.06.2019 в Нальчике под председательством заместителя министра просвещения Российской Федерации Андрея Николаева состоялось межрегиональное совещание по вопросам развития системы образования в субъектах СКФО, создания дополнительных мест в дошкольных учреждениях и ликвидации третьей смены обучения в общеобразовательных организациях округа.

Ассигнования, предоставляемые на эти цели из федерального бюджета, в том числе в рамках отраслевых национальных проектов, увеличены: «Добавлены субсидии на создание новых мест на селе, что особенно актуально для Северокавказского региона, реализацию программ модернизации учебного процесса. На увеличение мест в детских садах СКФО в рамках нацпроекта «Демографрия» в 2019 году будет направлено 11,7 млрд рублей. До 2024 года в детских садах на Северном Кавказе будет создано дополнительно 35 тысяч мест, что позволит удержать высокий уровень доступности дошкольного образования.

В реализации национального проекта «Демография» в части создания новых мест в образовательных организациях участвуют все субъекты СКФО: в 2019 году запланировано построить 89 объектов и создать 8715 новых мест [6]

Следующая выявленная проблема связана с поступлением детей в первый класс. Федеральным законом от 29 декабря 2012 года №273-Ф3 «Об образовании в Российской Федерации" за родителями закреплено право выбора образовательного учреждения, т.е. конкретной школы а также право на выбор профиля и обучающей программы. Условия поступления в первый класс установлены Порядком приема граждан на обучение по образовательным программам начального общего, основного общего и среднего общего образования, утвержденным Приказом Министерства образования и науки Российской Федерации от 22 января 2014 года №32, а также приказами или постановлениями органа местного самоуправления, приказом директора образовательной организации, в которых указываются, в том числе сроки приема документов

Практически повсеместно обнаружены ффакты нарушения образовательными организациями федеральных норм

Прокуратурой г. Карабулака Республики Ингушетия проведены надзорные мероприятия в сфере соблюдения образовательными организациями города требований федерального законодательства при приеме в образовательные организации

В ходе изучения локальных нормативных акТов ГБОУ «СОШ №3 г. Карабулака», регламентирующих правила приема обучающихся установлено, что Устав ГБОУ "СОШ №3 г. Карабулака» не соответствует требованиям фредерального законодательства

В пунктах 4.2.10 и 4.2.12 Устава указано, что прием заявлений в общеобразовательную организацию осуществляется с 1 апреля по 1 августа текущего года

Вместе с тем, Порядок приема устанавливает хронологическую последовательность и сроки а именно: прием в 1 класс заявлений от лиц, проживающих на закрепленной территории должен начинаться не позднее 1 февраля и завершаться не позднее 39 июня; от родителей детей, не проживающих на этой территории с 1 июля текущего года и длится до момента заполнения свободных мест, но не позднее 5 сентября. Ранее 1 июля могут открыть набор для лиц, не проживающих на территории общеобразовательные организации, закончившие прием всех детей по своей территории.

Пунктом 4.2 .5 устава предусмотрено, что для зачисления ребенка на обучение необходимо представить также медицинскую карту ребенка для образовательных учреждений; копию паспорта одного из родителей (законных представителей), копию СНИЛС, копию медицинского полиса, что тоже является нарушением федеральных норм (пункт 9).

В связи с вышеизложенным прокурором города в адрес директора СОШ №3 внесено представление об устранении выявленных нарушений закона [7]

Прокуратурой Назрановского района Республики Ингушетия проведена проверка соблюдения законодательства об образовании в общеобразовательных учреждениях на поднадзорной территории

В ходе проверки установлено, что в нарушение требований Закона «Об образовании в Российской Федерации» и Приказа Министерства образования и науки РФ от 22 января 2014 г. №32 , на официальных сайтах 22 школ района не размещена информация о количестве мест в первых классах, а также в установленный законом срок не опубликован распорядительный акт о закрепленной территории.

В соответствии с п.7 Порядка, государственные и муниципальные образовательные организации размещают распорядительный акт органа местного самоуправления муниципального района, городского округа (в городах федерального значения - акт органа, определенного законами этих субъектов Российской Федерации) о закреплении образовательных организаций за конкретными территориями муниципального района, городского округа, издаваемый не позднее 1 февраля текущего года

Согласно п. 8 Порядка, государственная или муниципальная образовательная организация с целью проведения организованного приема граждан в первый класс размещает на информационном стенде, на официальном сайте в сети «Интернет», в средствах массовой информации (в том числе электронных) информацию о: 
- количестве мест в первых классах не позднее 10 календарных дней с момента издания распорядительного акта о закрепленной территории;

- наличии свободных мест для приема детей, не проживающих на закрепленной территории, не позднее 1 июля.

Таким образом, родители дошкольников, желающие определить детей в первый класс данной школы, лишены возможности ознакомиться с предусмотренной законом информацией и решить вопрос о подаче заявления о приеме на обучение в данную образовательную организацию.

По результатам проверки прокурором района в адрес директоров 22 общеобразовательных учреждений внесены представления об устранении нарушений закона и привлечении виновных лиц к дисциплинарной ответственности

В поступивших к Уполномоченному по правам ребенка в Ставропольском крае обращениях от родителей по вопросам не зачисления ребенка в школу, как правило, причиной отказа указаны полная наполняемость классов. Подобные жалобы связаны с закрытостью и непрозрачностью системы зачисления в школы.

Существуют ли аналогичные социальные проблемы в Республике Южная Осетия?

Согласно статьи 28 Конституции Республики Южная Осетия каждый имеет право на образование и выбор форм его получения.

Южная Осетия относится к государствам с низкой плотностью населения. Недостаточность количества мест в дошкольных общеобразовательных учреждения, перегруженность в городских школах вызваны демографическими процессами.

В системе дошкольного образования Республики Южная Осетия 24 образовательных учреждения, осуществляющих образовательную деятельность по образовательным программам дошкольного образования и (или) присмотр и уход за детьми. Распределение дошкольных образовательных учреждений по районам выглядит следующим образом: г. Цхинвал - 17 (2711 чел.), Дзауский район - 2 (179), Знаурский район 2 (117), Ленингорский район - 2 (93), Цхинвальский район - 1 (92).

Средняя наполняемость в группах в городских детских садах - 29 человек, в сельских - 17 человек.

Количество детей, не обеспеченных местом в дошкольных образовательных организациях, 1544 человек (33\% от общего количеств детей; в 2018 году - 2065 человек или $40 \%$ ).

Общая численность детей, поставленных на учет для получения места в дошкольной образовательной организации, - 409 человек (прогнозируемое число детей в возрасте от 15 до 7 лет в 2021 году составляет 3542 человек).

За период 2015-2018 гг. создано 230 новых мест (70\% от запланированного), из них: в 2015 г. 100 мест - ДОО п. Дменис; в 2017 г. - 30 мест п. Орчосан - образовательная организация типа «школа-детский сад»; в 2018 г. - 100 мест - ДОО п. Ленингор
В целях обеспечения охвата и доступности дошкольного образования предполагается в г. Цхинвал завершение мероприятий по полному вводу эксплуатацию ДОО №17 (г. Цхинвал, Привокзальная площадь) на 100 мест. В 2019 г. планируется завершение строительства ДОО №1 (г. Цхинвал ул. Суворова) на 160 мест.

Согласно мероприятиям действующей Инвестиционной программы содействия социально-экономическому развитию Республики на 2018-2019 гт., в г. Цхинвал идет строительство многоквартирного жилого комплекса по ул. Бр. Губаевых, что приведет к увеличению численности детей дошкольного возраста в юго-восточной части г. Цхинвал. Вместе с тем одной из главных проблем остается проблема обеспеченности в юго-восточной части г. Цхинвала (р-н ЦАРЗ) услугами дошкольного образования, где численность детей от 0 до 7 лет на 1 января 2019 составляет 274 ребенка. Дети данного района входят в контингент воспитанников ДОО, расположенных в других районах города.

В ДОО № 12, рассчитанном на 100 детей, количество воспитаннике составляет 163. В ДоО № 5, мощность которого рассчитана на 140 детей, количеств воспитанников составляет 161. В ДОО № 6, контингент которого рассчитан на 140 детей, сегодня воспитываются и получают образование 170 детей. Контингент превышающий допустимую мощность, представлен детьми района ЦАРЗ (Бр. Губаевых).

В системе общего образования функционирует 40 общеобразовательных организаций (численность учащихся составляет 6093). Из них городских организаций - 12 (4833 человек), в сельской местности - 28 организаций (1260 человек). В государственных общеобразовательных организациях обучается 6093 ученика (в 2015 г. 5325), в негосударственных общеобразовательных организациях 441 человек (302). Статистические данные по средней наполняемости классов: в городе - 21,6 человек, в поселках 14,4; в отдаленных приграничных селах - 4 ученика.

На грани закрытия школы в населённых пунктах Балан, Ахмадж, Абрев и Хельчуа. В этих сельских школах по 1 или 2 ученика. При этом в каждой школе полный комплект учителей. К примеру, в отдаленном горном селе Балан Ленингорского района всего один ученик на всю школу [8]

Перегруженность допустимой проектной мощности школ в г. Цхинвал остается одной их ключевых проблем общего образования, несмотря на положительные изменения, происходящие в системе общего образования Республики Южная Осетия [10].

Итак, детское население в субъектах СКФО РФ и республике Южная Осетия увеличивается. Данный рост вызван демографическими и миграционными процессами

Ввод в эксплуатацию необходимых социальных объектов в микрорайонах активной жилищной застройки отстает от темпов ввода в эксплуатацию вновь построенного жилья. Отсюда растет 
нагрузка на некоторые образовательные организации, особенно в городах. Недостаточность мест в школах влечет за собой их переуплотненность нарушение санитарных норм и правил осуществления образовательного процесса.

Отдельно следует выделить вопрос о нарушении прав детей с инвалидностью в связи с отказами в приеме в коррекционные школы-интернаты при наличии мест, в вопросах доступности дошкольного образования детей данной категории. Система зачисления требует еще как нормативного совершенствования, так и информационной прозрачности.

Представляется, что иные, альтернативные муниципальным учреждениям, формы присмотра и ухода за детьми, получения ими дошкольного образования обеспечат доступность услуг дошкольного образования. С этой целью необходима целенаправленная государственная политика в отношении открытия и развития частных дошкольных общеобразовательных организаций, работа органов местного самоуправления по правовой, консультативной педагогической поддержке частных лиц, создающих негосударственные дошкольные образовательные организации

Право на образование относится к социальным правам гражданина [4, p. 171] и для их осуществления недостаточно воздерживаться от вмешательства в данную сферу, а необходимо продолжить вести целенаправленную государственную политику, которая позволила гарантировать провозглашенные права

\section{Литература}

1. Доклад о соблюдении прав и свобод человека и гражданина в Республике Ингушетия в 2018 году URL http://ingushombudsman.ru/annual_reports/doklad-o-soblyudenii-prav-i-svobod-tcheloveka-i-grazhdanina-v-respublikeingushetiya-v-2018-godu (Дата обращения: 22.07.2019).

2. Доклад о состоянии соблюдения прав и интересов ребенка в Кабардино-Балкарской Республике в 2017 году URL: http://deti.gov.ru/region/kbr/docs (Дата обращения: 22.07.2019).

3. Ежегодный доклад о состоянии и соблюдении прав и законных интересов детей в Ставропольском крае в 2018 году // Официальный сайт губернатора Ставропольского края URL: https://www.gubernator.stavkray.ru/contacts/rightschilds/item/9714-otchjot-upolnomochennogo-po-pravam-rebenka-za-2018-god.html (Дата обращения: 22.07.2019).

4. Енгибарян Р. В., Тадевосян Э. В. Конституционное право: учебник. М.: Юрист, 2000. 492 с.

5. Каштанова Е. А. О гарантии реализации права на образование // Вестник Омской юридической академии. 2017. №2. C. 24-28.

6. Информация Министерства просвещения, науки и по делам молодежи Кабардино-Балкарской республики // Официальный сайт Министерства просвещения, науки и по делам молодежи Кабардино-Балкарской республики. URL: http://pravitelstvo.kbr.ru/oigv/minobr/index.php?ELEMENT_ID=26110 22.07.2019 (Дата обращения: 20.07.2019).

7. Информация Прокуратуры Республики Ингушетия // Официальный сайт прокуратуры Республики Ингушетия URL: http://procing.ru/news/1975/?sphrase_id=3114 (Дата обращения: 23.07.2019).

8. Школа, встречай // Государственное информационное агентство «Pec». URL: http://cominf.org/node/1166524762 (Дата обращения: 25.08.2019).

9. Павлушкин А. В. Решения Конституционного Суда Российской Федерации в сфере образования //Комментарий судебной практики. Вып. 13. М.: Юрид. Лит., 2007. С. 27-43.

10. План модернизации сети дошкольного и общего образования Республики Южная Осетия на 2019-2021 гг. // Официальный сайт Министерства образования и науки Республика Южная Осетия URL: http://axwyrad.ru/upload/ibloc k/8f8/8f8a5a24342073ce6ec3f9680761e6cf.pdf (Дата обращения: 20.08.2019).

\section{References}

1. Doklad o sobljudenii prav i svobod cheloveka i grazhdanina $v$ Respublike Ingushetija $\vee 2018$ godu (Report on the observance of human and civil rights and freedoms in the Republic of Ingushetia in 2018). URL: http://ingushombudsman. ru/annual_reports/doklad-o-soblyudenii-prav-i-svobod-tcheloveka-i-grazhdanina-v-respublike-ingushetiya-v-2018-godu (Accessed: 22.07.2019). (In Russian).

2. Doklad o sostojanii sobljudenija prav i interesov rebenka v Kabardino-Balkarskoj Respublike v 2017 godu (Report on the state of observance of the rights and interests of the child in the Kabardino-Balkar Republic in 2017). URL: http://deti.gov.ru/ region/kbr/docs (Accessed: 22.07.2019). (In Russian).

3. Ezhegodnyj doklad o sostojanii i sobljudenii prav i zakonnyh interesov detej v Stavropol'skom krae v 2018 godu (Annual report on the state and observance of the rights and legitimate interests of children in the Stavropol territory in 2018) /I Oficial'nyj sajt gubernatora Stavropol'skogo kraja URL: https:/www.gubernator.stavkray.ru/contacts/rights-childs/item/9714otchjot-upolnomochennogo-po-pravam-rebenka-za-2018-god.html (Accessed: 22.07.2019). (In Russian).

4. Engibarjan R. V., Tadevosjan Je. V. Konstitucionnoe pravo: uchebnik (Constitutional law: textbook). Moscow: Jurist publ., 2000. 492 p.

5. Kashtanova E. A. O garantii realizacii prava na obrazovanie (On the guarantee of the right to education) // Vestnik Omskoj juridicheskoj akademii. 2017. No. 2. P. 24-28. (In Russian).

6. Informacija Ministerstva prosveshhenija, nauki i po delam molodezhi Kabardino-Balkarskoj respubliki (Information of the Ministry of education, science and youth Affairs of the Kabardino-Balkar Republic) // Oficial'nyj sajt Ministerstva prosveshhenija, nauki i po delam molodezhi Kabardino-Balkarskoj respubliki // URL: http://pravitelstvo.kbr.ru/oigv/minobr/ index.php?ELEMENT_ID=26110 22.07.2019 (Accessed: 20.07.2019). (In Russian).

7. Informacija Prokuratury Respubliki Ingushetija (Information Of The Prosecutor's Office Of The Republic Of Ingushetia) II Oficial'nyj sajt prokuratury Respubliki Ingushetija URL: http://procing.ru/news/1975/?sphrase_id=3114 (Accessed: 23.07.2019). (In Russian). 
8. Shkola, vstrechaj (School, meet) // Gosudarstvennoe informacionnoe agentstvo «Res». URL: http://cominf.org/ node/1166524762 (Accessed: 25.08.2019). (In Russian).

9. Pavlushkin A. V. Reshenija Konstitucionnogo Suda Rossijskoj Federacii v sfere obrazovanija (Decisions of the constitutional Court of the Russian Federation in the field of education) // Kommentarij sudebnoj praktiki. Issue 13. Moscow: Juridicheskaya literatira publ., 2007. P. 27-43. (In Russian).

10. Plan modernizacii seti doshkol'nogo i obshhego obrazovanija Respubliki Juzhnaja Osetija na 2019-2021gg. (Plan of modernization of preschool and General education network of the Republic of South Ossetia for 2019-2021) // Oficial'nyj sajt Ministerstva obrazovanija i nauki Respublika Juzhnaja Osetija URL: http://axwyrad.ru/upload/iblock/8f8/8f8a5a24342073ce6 ec3f9680761e6cf.pdf (Accessed: 20.08.2019). (In Russian).

\section{Сведения об авторах}

Терещенко Елена Анатольевна - кандидат юридических наук, заведующая кафедрой правовой культуры и защиты прав человека юридического института Северо-Кавказского федерального университета (Ставрополь) / Elena-tereshhenk@yandex.ru

Засеев Дзамболат Артурович - кандидат юридических наук, старший преподаватель кафедры уголовного права Юго-Осетинского государственного университета им. А.А. Тибилова (Цхинвал, Республика Южная Осетия) / zasseev13@mail.ru

\section{Information about the authors}

Tereshchenko Elena - PhD on Law, Head of Chair of Legal Culture and Protection of Human Rights, Institute of Law, North-Caucasus Federal University (Stavropol) / Elena-tereshhenk@yandex.ru

Zaseev Dzambolat - PhD on Law, Senior Teacher, Chair of Criminal Law, South-Ossetian State University named after A.Tibilov (Tskhinval, Republic of South Ossetia) / zasseev13@mail.ru 